\title{
New Zealand lessons may aid efforts to control light brown apple moth in California
}

\author{
by Lucia G. Varela, James T.S. Walker, \\ Peter L. Lo and David J. Rogers
}

New Zealand's major fruit industries are dependent upon producing highquality crops for export with a very low incidence of pest damage. Light brown apple moth was an economically important pest within the fruit sector in the 1960s through the 1980s, and it developed resistance to broad-spectrum insecticides. The increase in its pest status focused research on biological control, and existing native natural enemies were augmented with new introductions from Australia in the late 1960s. By the early 1990s, this effort resulted in substantially reduced leafroller populations and fruit damage. The implementation of integrated pest management (IPM) programs in the New Zealand fruit sector in the midto late 1990 s practically eliminated the use of broad-spectrum organophosphate insecticides, further enhancing natural control. Today light brown apple moth is successfully managed in IPM and organic programs through a combination of biological control and threshold-based applications of selective insecticides.

$\mathrm{T}$ he recent discovery of light brown apple moth, a leafroller, in California may affect the management of fruit crops, and because it is a quarantine pest in some markets, the discovery has already had implications for domestic and export trade in produce and nursery stock.

In New Zealand, light brown apple moth, Epiphyas postvittana (Walker) (Lepidoptera: Tortricidae), was first reported in 1891 (Hudson 1928). It became a major pest, primarily of pome

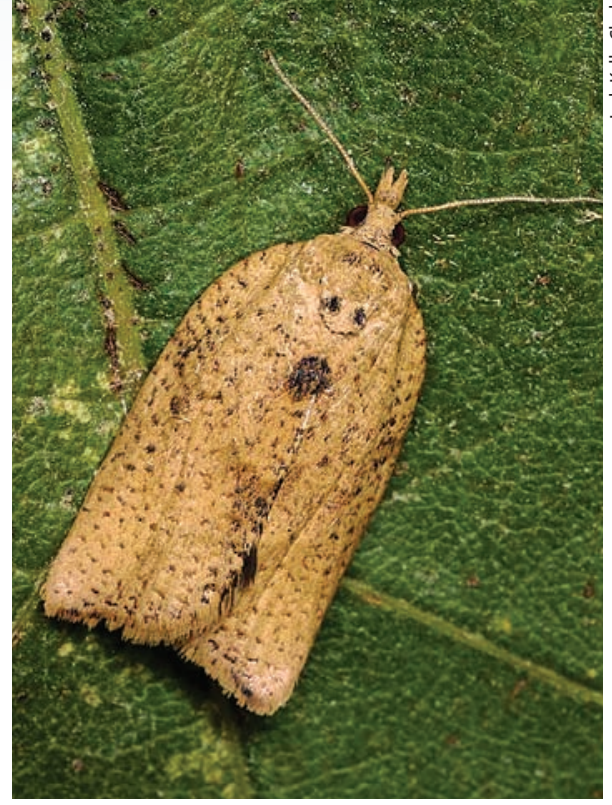

In New Zealand, light brown apple moth is controlled by parasitoids and selective insecticides.

fruit (apples and pears) and berry fruit, and a minor pest of grapes, citrus, stone fruit and kiwi fruit. The number of acres planted to pome and berry fruit - the crops most affected by light brown apple moth — is similar in New Zealand and California (table 1).

New Zealand went through a phase from the 1960s to 1980s when light brown apple moth caused major fruit damage; in apple crops this averaged from $8 \%$ to $26 \%$ and as high as $48 \%$ (Collyer and van Geldermalsen 1975). Control programs were based on frequent applications of broad-spectrum insecticides. This led to the development of resistance to organochlorines in the early 1960s (Collyer and van Geldermalsen 1975) and organophosphates by the early 1980s (Suckling et al. 1984; Suckling and Khoo 1990).

Over the last two decades, the pest status of light brown apple moth in New Zealand apples has shifted significantly. Damage has decreased to typically less than $2 \%$ in unsprayed trees (fig. 1). The decline in fruit damage is associated with lower leafroller density, which in turn is attributed to two key factors: (1) the introduction in the 1960s and subsequent spread of parasitoids attacking pupal and late larval stages 率 of light brown apple moth and (2) the change in fruit production programs from frequent applications of broadspectrum insecticides to less-intensive spraying with selective products.

By using a combination of natural control and selective insecticides, New Zealand growers are able to control light brown apple moth and meet the export standards of more than 60 countries that import a variety of fruit crops. In the 1980s, organophosphate insecticides were sprayed in six to nine applications each season on pome fruit crops for a variety of pests. Over the last decade, use of organophosphate insecticides has declined by $97 \%$, while the frequency of insecticide applications has declined by approximately 50\% (Manktelow et al. 2005). The insecticides now used are selective. The incidence of light brown apple moth fruit damage has declined, as has the larval incidence in crops.

In recent U.S. Department of Agriculture preclearance inspections of New Zealand apples grown using the Integrated Fruit Production program, the rejection rate of export consignments for the presence of light brown apple moth was typically less than $1 \%$. A consignment is rejected if one or more larva is detected in 20,000 individually inspected fruit.

\section{Biology and damage}

The light brown apple moth's biology was previously described in California Agriculture (Varela et al. 2008). In New Zealand, this insect reportedly feeds on 265 different host plant species

\begin{tabular}{|c|c|c|}
\hline Crop & New Zealand* & Californiat \\
\hline & \multicolumn{2}{|c|}{$\ldots \ldots \ldots$ acres (hectares) $\ldots \ldots$} \\
\hline Pome fruit & $23,539(9,526)$ & $36,500(14,771)$ \\
\hline Berry fruit & $5,913(2,393)$ & $7,400(2,994)$ \\
\hline Strawberries & $420(170)$ & $35,500(14,366)$ \\
\hline Grapes & $72,518(29,347)$ & $789,000(319,297)$ \\
\hline Citrus & $4,532(1,834)$ & $251,500(101,778)$ \\
\hline Stone fruit & $5,669(2,294)$ & $243,800(98,662)$ \\
\hline Kiwi fruit & $30,112(12,186)$ & $4,000(1,619)$ \\
\hline
\end{tabular}




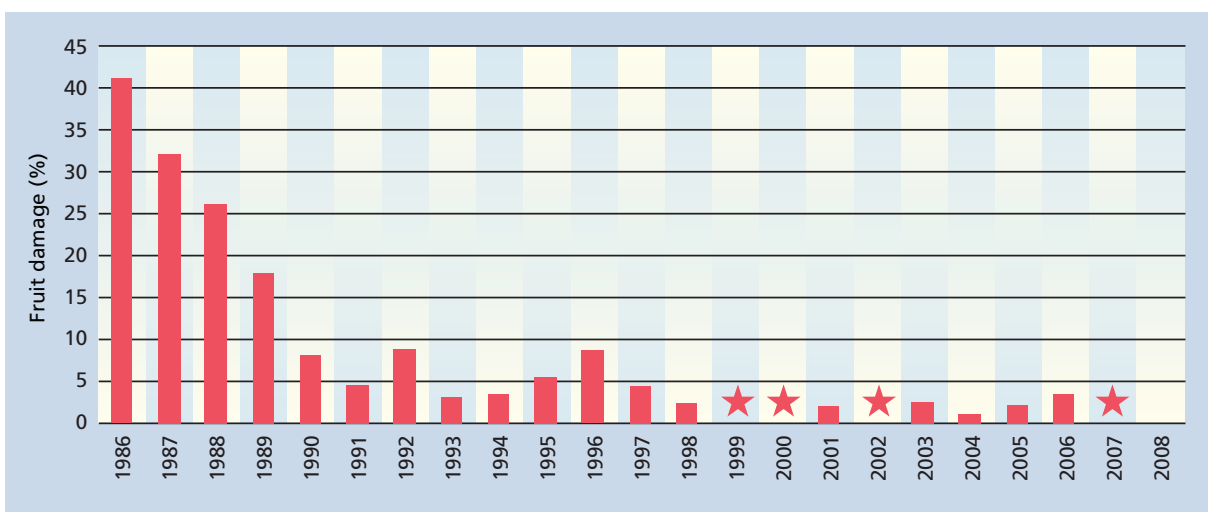

Fig. 1. Leafroller fruit damage on unsprayed apple trees in Hawke's Bay, New Zealand, 1986 to 2008 . $\star=$ no records kept.

(Thomas 1965), including fruit crops, ornamental plants, windbreak trees and broadleaf weeds.

This leafroller is predominantly a foliage feeder (Lo et al. 2000). The newly hatched larva spins a protective, silken, tubular shelter on the lower surface of leaves or ties together young leaves at shoot tips. Second and later stages may web leaves together or attach them to fruit. Fruit feeding is incidental and fruit damage is superficial; the penetration of fruit by larvae is uncommon. Fruit damage may increase during the season because of the larger fruit surface area in contact with leaves or other fruit (Lo et al. 2000).

New Zealand extends from $34^{\circ}$ to $47^{\circ}$ latitude (a geographic range similar to the lower 48 U.S. states) but has a maritime climate that is mild and relatively humid, similar to that of coastal California (fig. 2). The two major growing regions for New Zealand apples are Hawke's Bay and Nelson (Tasman). The climate of these two regions approximates that of California's Central Coast and North Coast, except that in New Zealand rainfall is year-round while in California precipitation is concentrated in fall and winter.

Light brown apple moth has four generations per year in northern North Island, three generations in the southern North Island and northern South Island, two to three generations in Canterbury and two generations in Central Otago (Wearing et al. 1991). The second- and third-generation larvae cause the most fruit damage (Collyer and van Geldermalsen 1975; Lo et al. 2000).

\section{Historical biological control}

A biological control program has evolved in New Zealand that suppresses light brown apple moth

populations. The effectiveness of this

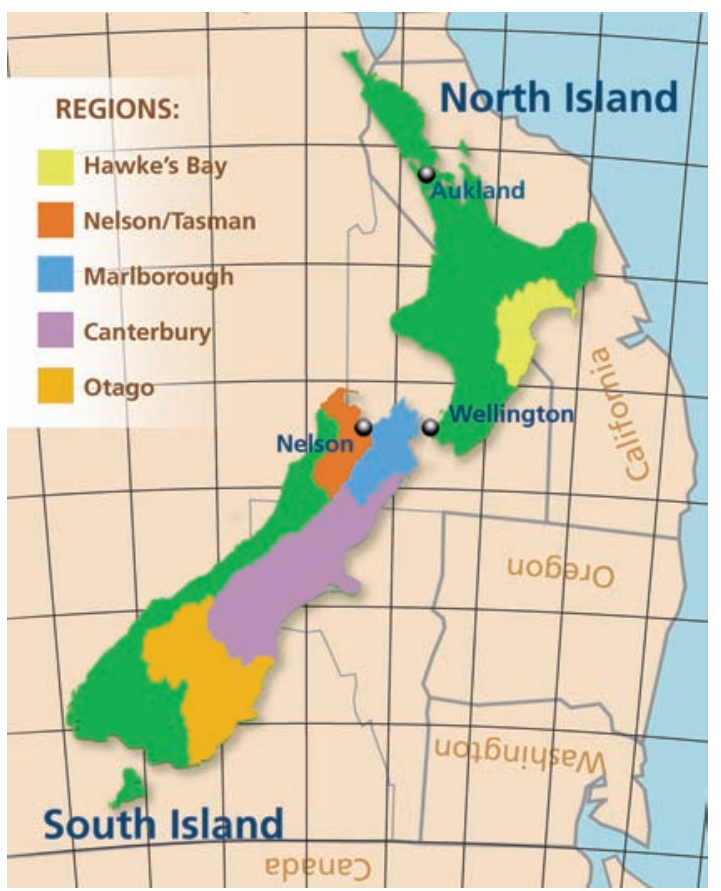
program relies on a complex of native and introduced natural enemies that attack all life stages (table 2) both in intensively managed fruit crops and the natural landscape. The reduction of broad-spectrum insecticide use since the late 1990s has enhanced natural control. The present state of biological control came about by (1) accidental introductions of parasitoids and predators, (2) the switching of hosts by some native natural enemies and (3) the deliberate introduction from 1967 to 1972 of parasitoids that attack the later stages of light brown apple moth.

An insect parasitoid completes its larval development on or inside a host. Most beneficial insect parasitoids are wasps or flies, the adult of which deposits one or more eggs on or inside a particular life stage (egg, larva or pupa) of its host. When the egg hatches, the parasitoid larva feeds on the host's tissue, ultimately killing the host as it matures and becomes free living as an adult. Endoparasitoids (endo) develop inside of the prey while ectoparasitoids (ecto) de-
Fig. 2. Major agricultural growing regions of New Zealand, and scale comparison with the U.S. West Coast (inverted to show corresponding latitudes).

velop outside of the host body. In some species, only one parasitoid will develop in or on each host (solitary); in others, several to hundreds of young larvae may develop from a single prey (gregarious).

L.J. Dumbleton $(1932,1935)$ was the first to report on natural enemies of the light brown apple moth in New Zealand. He listed Dolichogenidea tasmanica (Cameron) (Braconidae) as the most frequent parasitoid, found in $20 \%$ to $50 \%$ of the larvae reared. D. tasmanica attacks small leafroller larvae, depositing its eggs inside first- or second-instar larvae. The parasitoid larva develops inside its host and emerges from the third and fourth leafroller stage to form

\begin{tabular}{|c|c|c|c|c|c|}
\hline \multirow[b]{2}{*}{ Species } & \multirow[b]{2}{*}{ Family } & \multirow[b]{2}{*}{ Parasitoid type } & \multirow[b]{2}{*}{ Origin } & \multicolumn{2}{|c|}{ LBAM life stage/instar } \\
\hline & & & & Attack & Emerge from \\
\hline $\begin{array}{l}\text { Dolichogenidea } \\
\text { tasmanica }\end{array}$ & Braconidae & Solitary, endo* & $\begin{array}{l}\text { Accidentally } \\
\text { introduced }\end{array}$ & First and second & Fourth \\
\hline $\begin{array}{l}\text { Glyptapanteles } \\
\text { demeter }\end{array}$ & Braconidae & Gregarious ${ }^{\dagger}$, endo & Endemic & Third and fourth & Late larval \\
\hline Goniozus jacintae & Bethylidae & Gregarious, ecto $\ddagger$ & Australia & Second to fourth & Late larval \\
\hline $\begin{array}{c}\text { Trigonospila } \\
\text { brevifacies }\end{array}$ & Tachinidae & Solitary, endo & Australia & Third to fifth & $\begin{array}{l}\text { Mid- to late } \\
\text { larval or pupal }\end{array}$ \\
\hline Pales funesta & Tachinidae & Solitary, endo & Endemic & Fourth to fifth & Late larval \\
\hline $\begin{array}{l}\text { Xanthopimpla } \\
\text { rhopaloceros }\end{array}$ & Ichneumonidae & Solitary, endo & Australia & Pupal & Pupal \\
\hline $\begin{array}{l}\text { Glabridorsum } \\
\text { stokesii }\end{array}$ & Ichneumonidae & $\begin{array}{l}\text { Solitary, ecto/ } \\
\text { endo }\end{array}$ & Australia & Pupal & Pupal \\
\hline \multicolumn{6}{|c|}{$\begin{array}{l}\text { * Parasitoid develops within its host. } \\
\text { † More than one parasitoid develops per host. } \\
\text { ‡ Parasitoid develops outside its host. }\end{array}$} \\
\hline
\end{tabular}


With a strategic commitment to biological control within an IPM context, California may ultimately achieve the same levels of light brown apple moth control as obtained in New Zealand.

a cocoon inside the webbed nest next to the consumed leafroller larva (Paull and Austin 2006). D. tasmanica was accidentally introduced to New Zealand, probably with light brown apple moth from Australia (Dumbleton 1935).

Dumbleton (1936) reported only one early parasitoid importation from Australia in 1922; it was later identified as Goniozus jacintae Farrugia (Bethylidae) (Berry 1998). This parasitoid lays one or more eggs externally in the folds between segments of third- to sixth-stage caterpillars (Danthanarayana 1980). The parasitoid larvae feed externally and later form cocoons inside the nest formed by the leafroller. The rest of the species Dumbleton described attacking light brown apple larvae either had arrived with light brown apple moth or were native to New Zealand. Two native parasitoids identified by Dumbleton are still frequently encountered: the gregarious endoparasitoid Glyptapanteles demeter (Wilkinson) (Braconidae), which attacks third- and fourth-stage leafroller larvae, and the tachinid fly Pales funesta (Hutton), which attacks fourth and fifth larval stages.

G. demeter is the most frequently cited native parasitoid attacking light brown apple moth. In a study conducted in organic apple orchards, Dolichogenidea spp. was the most abundant parasitoid attacking leafrollers found in the apple foliage; G. demeter was the dominant parasitoid reared from leafrollers collected from broadleaf weeds in the apple orchard understory (Rogers et al. 2003).

Thomas (1989) reported 19 species of parasitoids reared from light brown apple moth eggs, larvae and pupae collected in New Zealand prior to 1967. D. tasmanica was the most abundant, and few parasitoids attacked the later larval and pupal stages. Trichogrammatid parasitoids, including Trichogramma funiculatum and Trichogrammatoidea bactrae, parasitized the eggs of light brown apple moth with wide variation in parasitism levels, rarely rising above 10\% (Thomas 1989; Stevens 1995).
In 1967 and 1969, Thomas collected parasitoids in the eastern temperate areas of Australia, from Sydney in New South Wales to Hobart in Tasmania. Of the specimens collected, six species that attack late leafroller stages were released between 1967 and 1972. Five species successfully established themselves, but only three that attack light brown apple moth became relatively widespread. These three species are the tachinid fly Trigonospila brevifacies (Hardy), which attacks late larval stages, and the pupal ichneumonid parasitoids Xanthopimpla rhopaloceros Krieger and Glabridorsum stokesii (Cameron). All three species had been released at several locations in the North Island, and in the Nelson area and Canterbury in the South Island. In 1999, T. brevifacies was rereleased in the Nelson area, using specimens collected in Hawke's Bay (Shaw et al. 2001).

In surveys conducted in 1996 and 1997 (Munro 1998), X. rhopaloceros and T. brevifacies were found throughout the North Island and the north end of the South Island. Both species failed to establish in Canterbury. X. rhopaloceros had a faster rate of spread than T. brevifacies; X. rhopaloceros was first reported established in the north end of the North Island in 1973. Published reports in 1975 and 1976 indicate that this species appeared in Auckland in numbers large enough that the public made inquiries to the authorities (Munro 1998). By the late 1970s and early 1980s it was recorded in the south of the North Island, becoming widespread in Hawke's Bay by 1985 and in Nelson by 1992.

T. brevifacies was first reported as established in the northern tip of the North Island in 1972. Archival records show that it was found in the northern part of the island in the 1980s, moving through the western side and reaching Wellington (in southern North Island) in 1998. Recorded finds from the eastern North Island began in the early 1990s with reports from Hawke's Bay in 1995. In the South Island the first reports were from Nelson in 1997.

Although the impacts of T. brevifacies and $X$. rhopaloceros have not been
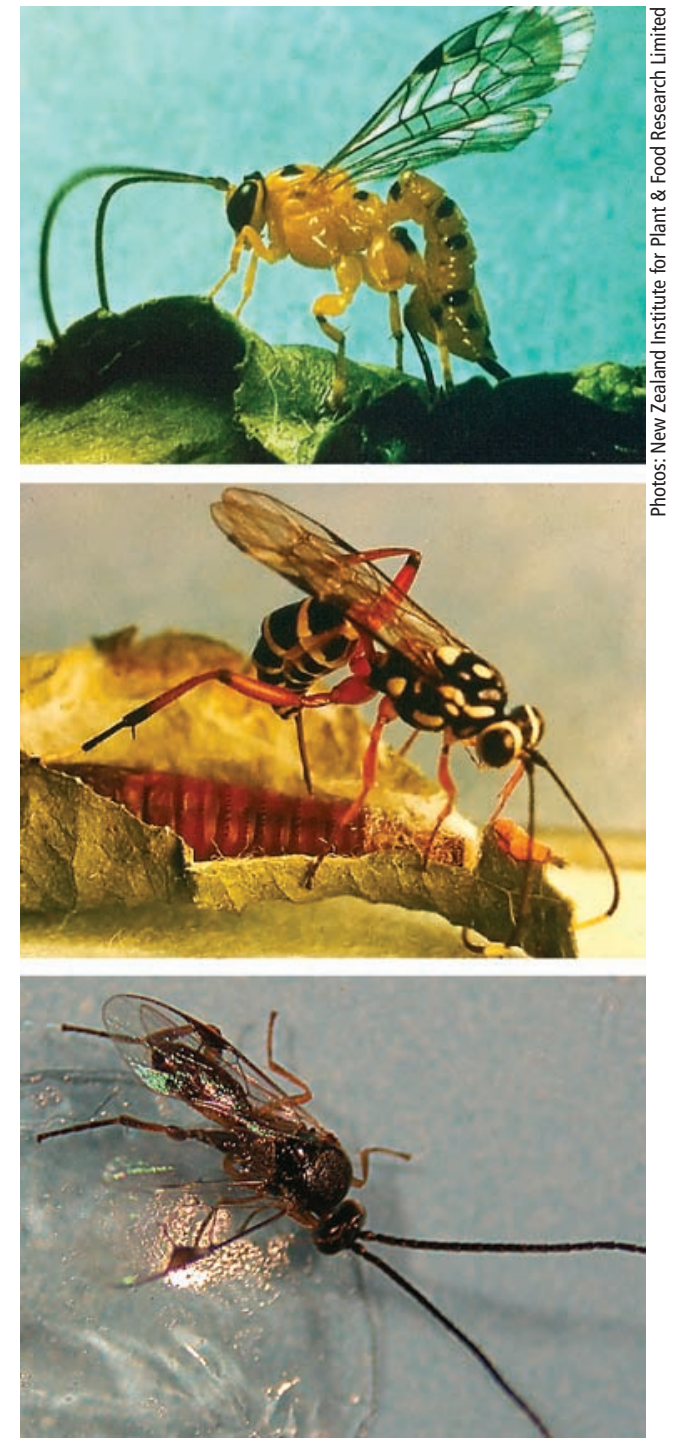

Parasitoids are insects that complete their development inside a host. A number of them are known to attack light brown apple moth, including, top, Xanthopimpla rhopaloceros, center, Glabridorsum stokesii and, bottom, Dolichogenidea tasmanica.

quantified, there is indirect evidence that they have contributed to significant declines in larval fruit-feeding damage by light brown apple moth, and consequently to reduced insecticide use. These generalist parasitoids, in particular T. brevifacies, also have had an impact on endemic leafroller species and are likely to compete with native parasitoids in the natural environment (Munro and Henderson 2002), but since no prerelease data on the relative abundance of lepidopteran species was gathered, it is difficult to determine the exact impact. Before any proposed introduction of the natural enemies, possible impacts on both native hosts and natural enemies should be considered. 


\section{Current biocontrol strategies}

Leafroller larvae and pupae (predominantly light brown apple moth) and parasitoid cocoons were collected from orchards and vineyards in Hawke's Bay between 1993 and 2009 (Lo, unpublished data). These specimens were reared to determine which species of leafroller or parasitoid emerged. D. tasmanica remains the most abundant leafroller parasitoid, comprising $66 \%$ to $97 \%$ of the parasitoids reared from apple and stone fruit trees, berry fruit and grapevines. The next most abundant parasitoids were T. brevifacies $(1 \%$ to $27 \%)$, G. demeter ( $2 \%$ to $16 \%$ ) and Goniozus jacintae ( $2 \%$ to $12 \%$ ). D. tasmanica comprised $90 \%$ of the parasitoids reared from the first four larval instars, reducing light brown apple moth larvae by $85 \%$ on average. A high proportion of neonate light brown apple moth larvae fail to settle and establish successful leafrolls, and die before reaching the second instar. Later larval stages are then subjected to high levels of parasitism that potentially further reduced light brown

\section{National Research Council reviews pest status of light brown apple moth}

by Rhonda J. Smith

IN 2007, the light brown apple moth was classified by the U.S. Department of Agriculture's Animal Plant Health and Inspection Service (APHIS) as an actionable, quarantine-significant pest, meaning that its presence has potentially significant economic importance. Its presence in California resulted in a federal order restricting the interstate movement of specific agricultural commodities and their byproducts from affected counties. To meet the federal order, the moth is subject to quarantine and eradication efforts by both APHIS and the California Department of Food and Agriculture (CDFA).

In 2009, more than 3,500 square miles of California were in the quarantine area. Growers and others who move regulated articles off-site are required to have compliance agreements with the county agricultural commissioner's office. In Sonoma County, for example, affected commodities include wine grapes, apples, cane berries, strawberries, nursery stock, cut flowers and most vegetables and herbs, as well as green waste. Compliance agreements are also required of the entity that receives product, such as wineries, processing and packing plants. Wine-grape haulers are required to have compliance agreements if they transport grapes from a quarantine area.

In September 2008 and February 2009, APHIS received one petition from four citizens, and another from the Pesticide Action Network of North America plus other organizations, requesting that light brown apple moth be reclassified from an actionable to a nonactionable pest. In addition, the petitioners argued against eradication as a feasible regulatory action. In June 2009, APHIS wrote a draft response to the petitions and requested that it be reviewed by the National Research Council (NRC).

The NRC's September 2009 "Letter Report" addressed whether the federal government had the regulatory authority to classify light brown apple moth as an actionable, quarantine-significant pest, and evaluated both the scientific basis for this regulatory decision and the quality of the evidence presented.

The 31-page report had two takehome messages. First, APHIS did have the authority to classify light brown apple moth as an actionable pest and thus could take regulatory action. Second, the evidence used as the basis for the classification decision was insufficient and unclear, and in some instances the evidence was not clearly supported by the data provided.

Finding 1: Only qualitative, rather than quantitative, criteria on economic/ environmental damage are required for the Secretary of Agriculture to determine a regulatory response to a pest. APHIS met the minimal standard by providing evidence of the moth's potential invasive nature and economic and environmental impacts, but the agency's justification is not scientifically rigorous.

Finding 2: The data used to predict the potential geographic distribution of light brown apple moth in the United States and the subsequent economic impact analyses are not based on "sound, rigorous science."

Finding 3: The evidence presented to make estimates of the potential economic damage to agricultural production and trade, as well as environmental damage to native and endangered plant species, is not evaluated consistently and has limitations that are not clearly acknowledged or explained.

Finding 4: The credibility of the response is undermined by factors such as inadequately documented statements and scientifically imprecise terminology.

Finding 5: APHIS has not published a proposed or final rule of the federal order in the Federal Register for comment under the Administrative Procedure Act and missed the opportunity to justify its actions to the public.

Finding 6: APHIS chose to limit the scope of its response by not addressing the use of eradication as the current control strategy, and thus "may have exacerbated public concerns about the eradication effort."

The NRC scientists could only address what was contained in the APHIS response; however, they emphasized that APHIS did not include a rationale for choosing eradication, which is one of several possible approaches to control a regulated pest. Instead, APHIS restricted its response to the issue of the light brown apple moth's classification status and missed an opportunity to explain its decisions to the general public.

It is important to read the full NRC Letter Report, which recommends that APHIS refocus on the question of why this pest is so important to the United States and base their response on a detailed economic analysis.

Go to: http://www.nap.edu/catalog. php?record_id=12762. For information on CDFA's Light Brown Apple Moth Project, go to: http://www.cdfa.ca.gov/phpps/PDEP/ lbam/lbam_main.html.

R.J. Smith is Viticulture Farm Advisor, UC Cooperative Extension, Sonoma County. 


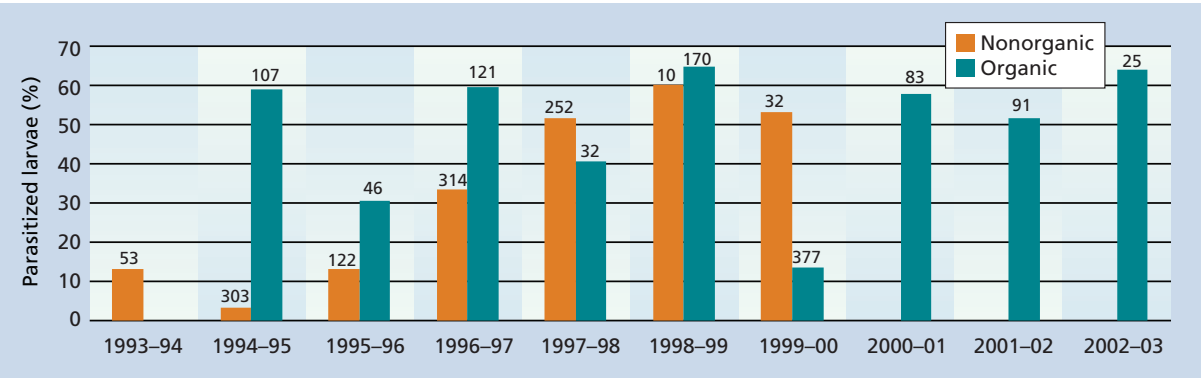

Fig. 3. Parasitized leafroller larvae from apple orchards in Hawke's Bay, New Zealand. Yearly sample size is at the top of each column.

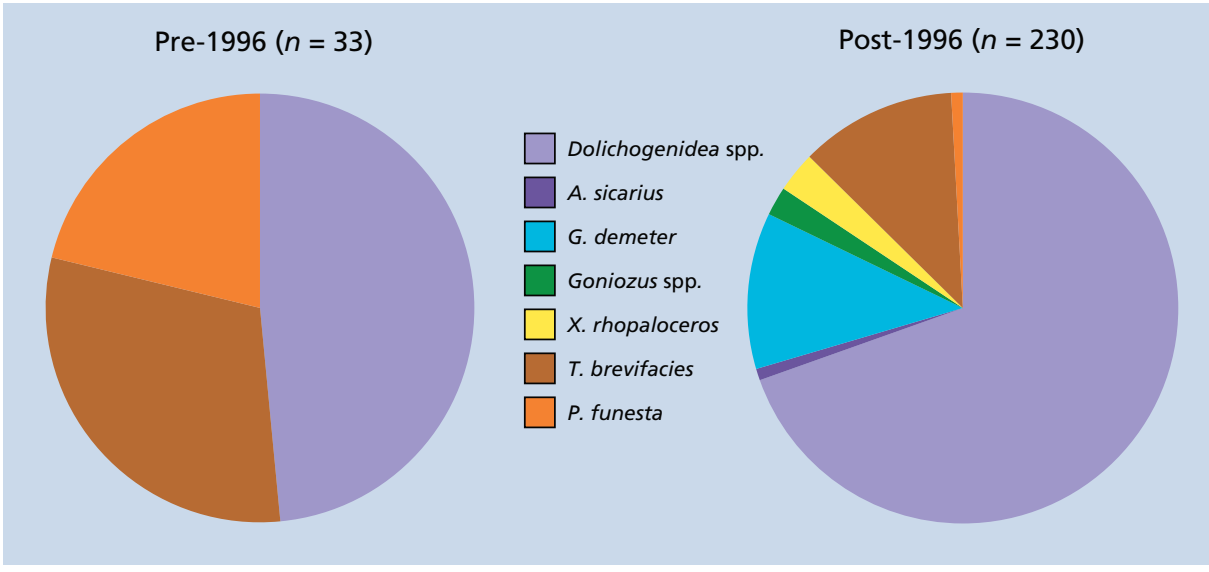

Fig. 4. Parasitoid species reared from leafrollers collected in nonorganic apple orchards in Hawke's Bay, New Zealand, 1993-1995 and 1996-2000.

apple moth populations by an estimated 95\% (Lo, unpublished data).

It is difficult to compare the relative importance of each natural enemy without a comprehensive life-table study. Nevertheless, the significance of D. tasmanica is evident in the relatively high percentage of parasitism of young larvae (about $50 \%$ of instar stages two to four) compared with later immature stages (about 20\%). Although the later parasitoids are less abundant than D. tasmanica, their importance should not be underestimated. They are removing leafrollers that are more likely to breed and contribute to the growth of subsequent populations.

Perhaps the large increase in parasitism in New Zealand apple orchards during the 1990s also reflected the coincidental change from broadspectrum to selective insecticides such as insect growth regulators. Many broad-spectrum insecticides are nerve poisons and consequently are toxic to both pests and beneficial species. In contrast, selective insecticides act on metabolic pathways of pests but not those of natural enemies, and therefore have substantially lower toxicity to the latter, in particular parasitoids. In 1996, the New Zealand apple industry began implementing the Integrated Fruit Production Program (Walker et al. 1997), and within 5 years the industry had substantially eliminated broadspectrum organophosphates from their spray schedules (Manktelow et al. 2005).

To address changing European duced using environmentally sustainable production systems, a pilot Integrated Fruit Production Program was initiated in pome fruit throughout New Zealand in 1996. In this program, insect control relied on the increased use of biological control, monitoring reduced-risk insecticides - those compatible with integrated pest management (IPM) (Walker et al. 1997). Light brown apple moth control is based on one recommended application of an insecticide at petal fall (early November). Any subsequent insecticide use after Dec. 15 is based on a cumulative threshold of 30 male moths caught in pheromone traps.

The program was progressively adopted by growers and became the minimum export standard by 2001 . Total organophosphate insecticide use decreased from an average of 9 applications per season in 1996 to 0.3 applicaUnion market demands for fruit proand threshold-based applications of tions in 2003 (Manktelow et al. 2005). After 2001, just one or two reduced-risk insecticide applications may be required for light brown apple moth control when fruit are grown for domestic consumption. For export apples, pest management is largely driven by codling moth control. This, together with the increased levels of biological control, provides a very high level of management of light brown apple moth.

The impact of the replacement of organophosphate insecticides on biological control was demonstrated in Hawke's Bay apple orchards. The proportion of parasitized leafroller larvae and pupae from nonorganic apple orchards increased significantly between 1993 and 1994, and between 1999 and 2000 (fig. 3) (Lo, unpublished data). Of 478 leafrollers collected from 23 orchards between 1993 and 1995, 7\% were parasitized. In contrast, from 1996 to 2000, 604 leafrollers were collected from 19 orchards, and $42 \%$ were parasitized. In 1998, after implementation of the Integrated Fruit Production Program, it became increasingly difficult to find leafroller infestations in nonorganic apple orchards. By 2000, the whole sector had adopted Integrated Fruit Production practices, and larval collections ended because of the scarcity of leafroller fruit damage. In organic apple orchards where there was no major change in spray programs between 1993 and 2003, parasitism was high throughout this period, albeit with some annual fluctuations.

In addition to an increase in parasitism after the change to selective insecticides, there is also a greater diversity in the parasitoid fauna attacking leafrollers in New Zealand. In nonorganic apple orchards, three parasitoid species were reared from pre-1996 collections compared with seven species in later years (fig. 4). In studies conducted in berry fruit in 1985 and 1986 in Hawke's Bay (Charles et al. 1996), 14\% to $70 \%$ of larvae collected and reared were parasitized. More than $90 \%$ of the parasitoids reared were the solitary species $D$. tasmanica. The remaining were the gregarious larval parasitoids G. demeter and Goniozus spp. Parasitism of larvae and pupae collected from berries was 62\% from 1996 to 1999 , and $79 \%$ from 2008 to 2009 (Lo, unpublished data). D. tasmanica was less dominant than in the Charles et al. (1996) 
study, because T. brevifacies and Meteorus pulchricornis were found in addition to G. demeter and Goniozus spp.

\section{Current insecticide use}

The selective insecticides used in pome fruit today in New Zealand primarily target codling moth, but they are also effective against light brown apple moth and provide high levels of control. They include tebufenozide (Confirm), methoxyfenozide (Intrepid), indoxacarb (Avaunt), chlorantraniliprole (Altacor) and emamectin benzoate (Proclaim). All are effective and provide long residual control with low to moderate impacts on beneficial natural enemies. About $8 \%$ of the New Zealand apple crop is grown organically; the insecticides used in these orchards include spinosad (Entrust) and Bacillus thuringiensis (Bt). Significant proportions of organic growers successfully produce export apple crops using mating disruption for codling moth control without any use of these insecticides, and they suffer only negligible fruit damage from light brown apple moth.

Some of the new insecticides are significantly less disruptive to natural enemies than the broad-spectrum organophosphates used in the past. Residual bioassays measuring the effects of field application rates of insecticides to $D$. tasmanica showed that tebufenozide and emamectin benzoate were harmless (less than $21 \%$ mortality) to adults 7 days after treatment. Indoxacarb and lime-sulfur residues caused $80 \%$ to 99\% mortality, while carbaryl (Sevin), diazinon and spinosad (Success) were very harmful (more than 99\% mortality) (Newman et al. 2004). These toxicity categories followed the standard criteria for laboratory studies defined by the International Organization for Biological and Integrated Control of Noxious Animals and Plants (Hassan 1985).

By early 2000, all of New Zealand's major fruit industries had imple- mented programs based on the concepts embodied within Integrated Fruit Production: use of thresholds for pesticide inputs, with an emphasis on selective control options (Manktelow et al. 2005). Wine-grape industry records show that, for leafroller control, national insecticide use has shifted from an average of one organophosphate application in 1997 to less than 0.4 insect growth regulator applications by 2008. The two insect growth regulator insecticides used in wine grapes for leafroller control are tebufenozide and methoxyfenozide. The need for an application is determined by damage observed during the previous harvest. When treatment is needed, a single prebloom spray is applied.

\section{Considerations for California}

With a strategic commitment to biological control within an IPM context, California may ultimately achieve the (continued on next page)

\section{References}

Berry JA. 1998. The bethyline species (Hymenoptera: Bethylidae: Bethylinae) imported into New Zealand for biological control of pest leafrollers. NZ J Zool 25:329-33

Charles JG, Walker JTS, White V. 1996. Leafroller phenology and parasitism in Hawkes Bay, New Zealand, canefruit gardens. NZ J Crop Hort Sci 24:123-31.

Collyer E, van Geldermalsen M. 1975. Integrated control of apple pests in New Zealand. 1. Outline of experiment and general results. NZ J Zool 2:101-34.

Danthanarayana W. 1980. Parasitism of the light brown apple moth Epiphyas postvittana (Walker), by its larval ectoparasite, Goniozus jacintae Farrugia (Hymenoptera: Bethylidae), in natural populations in Victoria. Aust J Zool 28:685-92.

Dumbleton LJ. 1932. The apple leaf-roller (Tortrix postvittana Walker). NZ J Sci Tech 14:83-92.

Dumbleton LJ. 1935. Apanteles tasmanica Cam., a braconid parasite of leafroller larvae. NZ J Sci Tech 17:572-6.

Dumbleton LJ. 1936. The biological control of fruit pests in New Zealand. NZ J Sci Tech 18:588-92.

Hassan SA. 1985. Standard methods to test the sideeffects of pesticides on natural enemies of insects and mites developed by the IOBCMPRS Working Group Pesticides and Beneficial Organisms. Bull OEPP/EPPO $15: 214-55$

Hudson GV. 1928. The Butterflies and Moths of New Zealand. Wellington, New Zealand: Ferguson Osborn $386 \mathrm{p}$.

Lo PL, Suckling DM, Bradley SJ, et al. 2000. Factors affecting feeding site preferences of lightbrown apple moth, Epiphyas postvittana (Lepidoptera: Tortricidae), on apple trees in New Zealand. NZ J Crop Hort Sci 28:235-43.
Manktelow D, Stevens P, Walker JTS, et al. 2005. Trends in Pesticide Use in New Zealand: 2004. Report to the Ministry of Environment, Project SMF4193. 73 p.

Munro VMW. 1998. A record of the releases and recoveries of the Australian parasitoids Xanthopimpla rhopaloceros Krieger (Hymenoptera: Ichneumonidae) and Trigonospila brevifacies Hardy (Diptera: Tachinidae) introduced into New Zealand for leafroller control. NZ Entomol 21:81-91.

Munro VMW, Henderson IM. 2002. Nontarget effect of entomophagous biocontrol: Shared parasitism between native lepidopteran parasitoids and the biocontrol agent Trigonospila brevifacies (Diptera: Tachinidae) in forest habitats. Env Entomol 31:388-96.

Newman IC, Walker JTS, Rogers DJ. 2004. Mortality of the leafroller parasitoid Dolichogenidea tasmanica (Hym: Braconidae) exposed to orchard pesticide residues. NZ Plant Protect 57:8-12.

Paull C, Austin AD. 2006. The hymenopteran parasitoids of light brown apple moth, Epiphyas postvittana (Walker) (Lepidoptera: Tortricidea) in Australia. Aust J Entomol 45:142-56.

Plant \& Food Research. 2008. Fresh Facts: New Zealand Horticulture 2008. http://www.hortresearch.co.nz/files/ aboutus/factsandfigs/ff2008.pdf. 36 p

Rogers DJ, Walker JTS, Moen IC, et al. 2003. Understory influence on leafroller populations in Hawke's Bay organic apple orchards. NZ Plant Protect 56:168-73.

Shaw PW, Lo P, Wallis DR. 2001. Recent introduction and establishment of the leafroller parasitoid Trigonospila brevifacies (Hardy) (Diptera: Tachinidae) in Nelson. NZ Plant Protect 54:33-6.

Stevens PS. 1995. Host preferences of Trichogrammatoidea bactrae fumata (Hym.: Trichogrammatidae) an egg parasitoid of leafrollers (Lep.: Tortricidae). Entomophaga 40:379-85.
Suckling DM, Chapman RB, Penman DR. 1984. Insecticide resistance in the lightbrown apple moth Epiphyas postvittana (Walker): Larval responses to azinphosmethyl. J Econ Entomol 77:579-83.

Suckling DM, Khoo JGI. 1990. Cross-resistance in the lightbrown apple moth Epiphyas postvittana (Lepidoptera: Tortricidae). NZ J Crop Host Sci 18:173-80.

Thomas WP. 1965. Studies on Epiphyas postvittana (Walker) (Lepidoptera, Tortricidae) and its parasitoid complex. M.Sc. thesis, University of Canterbury. $130 \mathrm{p}$

Thomas WP. 1989. Epiphyas postvittana (Walker) lightbrown apple moth (Lepidoptera: Tortricidae). In: Cameron PJ, Hill RL, Bain J, Thomas WP (eds.). A Review of Biological Control of Invertebrate Pests and Weeds in New Zealand, 1874 to 1987. Wallingford, UK: CAB Int. p 187-95

[USDA NASS] US Department of Agriculture National Agricultural Statistics Service. 2008. California Agricultural Statistics, Agricultural Overview 2007. http://www.nass.usda.gov/Statistics_by_State/ California/Publications/California_Ag_Statistics. 10 p.

Varela LG, Johnson MW, Strand L, et al. 2008. Light brown apple moth's arrival in California worries commodity groups. Cal Ag 62:57-61.

Walker JTS, Hodson AJ, Wearing CH, et al. 1997. Integrated fruit production for New Zealand pipfruit: Evaluation of pest management in a pilot programme. Proc 50th NZ Plant Protect Conf. p 258-63.

Wearing $\mathrm{CH}$, Thomas WP, Dugdale JS, Danthanarayana W. 1991. Tortricid pests of pome and stone fruits, Australian and New Zealand species. In: Tortricid Pests: Their Biology, Natural Enemies and Control; World Crop Pests, Vol. 5. Amsterdam: Elsevier. p 453-72. 
(continued from previous page)

same levels of light brown apple moth control as obtained in New Zealand. Many fruit crops in California already receive control measures for native and introduced leafrollers, and these tactics may prove to be effective for light brown apple moth without a great deal of modification.

If the New Zealand experience is any indication, adequate control of this leafroller can be achieved more effectively through a vigorous program of biological control and the use of selective insecticides for other pest species. That approach identified a need to introduce natural enemies to attack light brown apple moth through all stages of development. The focus on introductions to address parasitism gaps, especially those targeting the late larval and pupal stages, proved to be highly effective. Further exploration of natural enemies in New Zealand may yield guidance for possible parasitoid importations to North America.

As New Zealand has already found, it is unlikely that any one parasitoid will be so specific that it attacks only light brown apple moth. Therefore, any introduction of natural enemies into California must be preceded by a careful cost-benefit analysis. Light brown apple moth is a polyphagous insect, feeding on many plant species, and some native leafrollers may occupy the same niche. The benefit of suppressing populations of light brown apple moth and allowing reduced use of insecticide must outweigh possible adverse impacts on populations of endemic moths and natural enemies. This is an issue that must be carefully considered in the development of a strategic plan for the long-term management of this pest in California.

L.G. Varela is Integrated Pest Management (IPM) Advisor, UC Statewide IPM Program and UC Cooperative Extension; and J.T.S. Walker is Senior Fruit Crop Entomologist, P.L. Lo is Senior Scientist, and D.J. Rogers is Senior Scientist, The New Zealand Institute for Plant \& Food Research Limited, Hawkes Bay, New Zealand.

References (see page 11)

\section{Airborne particles in the San Joaquin Valley may affect human health}

by Mai A. Ngo, Kent E. Pinkerton, Sandra Freeland, Michael Geller, Walter Ham, Steven Cliff, Laurie E. Hopkins, Michael J. Kleeman, Urmila P. Kodavanti, Emily Meharg, Laurel Plummer, Julian J. Recendez, Marc B. Schenker, Constantinos Sioutas, Suzette Smiley-Jewell, Christine Haas, Joyce Gutstein and Anthony S. Wexler

\section{Air quality is a primary concern for} many San Joaquin Valley residents. In addition to rapid population growth, a widening interface between urban and agricultural communities, and increasing traffic along the I-5 and Hwy. 99 corridors, farming practices in the San Joaquin Valley subject agricultural workers to high concentrations of airborne particulate matter potentially associated with adverse health effects. We created a research team and mobile field unit equipped with a special inhalation system, particle monitoring and characterization abilities, and housing for the transport and care of animals to examine the effects of particulate matter throughout the San Joaquin Valley. With this system, a variety of biological endpoints can be examined to determine respiratory, systemic and neurological responses to short-term particle exposure. Field research of this nature coupled with biological assays and location-specific inhalation studies can help researchers and regulators to better understand potential health effects due to environmental and occupational airborne-particle exposures faced by workers and residents in the San Joaquin Valley. $\triangle$ griculture is a major industry in in 2007 (CDFA 2009). The state claims nine of the 10 most productive counties in the nation. The majority are in the
San Joaquin Valley, which extends approximately 250 miles from San Joaquin County in the north to Kern County in the south. San Joaquin Valley agriculture encompasses more than 400 plant and animal commodities - with Fresno and Tulare counties leading in agricultural value for the production of grapes, almonds, milk, oranges and cattle. Approximately 4 million people live in the San Joaquin Valley (State of California 2007) and the number of farmworkers is estimated to be between 175,000 to 500,000 .

While the San Joaquin Valley is one of the world's most productive agricultural regions, it is also frequently in violation of U.S. ambient air-quality concentration standards, particularly those for atmospheric particulate matter (PM) (Velasco 2005), which is defined as liquid or solid material such as soil dust or smoke suspended in the air. Particulate levels for the South Coast Air Basin and the Central Valley in California are the highest recorded in the country, exceeding the national ambient air-quality standards for each season of the year. Workers and residents of the San Joaquin Valley are exposed to airborne particulate matter from a broad range of sources including farming practices such as the tilling of dry soil, agricultural burning, crop harvesting and diesel-powered water pumping. Particle emissions include inorganic compounds from soil lofted by, for example, dairy operations and off-road vehicles, or organic matter from animal feed and disturbed, dried manure.

The three parameters - size, composition and distribution - for each classification of particles are sufficiently different that each can produce unique health outcomes following inhalation. Epidemiological studies have shown a strong correlation between the exposure of human populations to particulate matter and acute and chronic health effects, including increased deaths due to cardiovascular illness and emergency room visits related to the severity of asthma symptoms (Sheppard 